\title{
Governing by expertise: the contested politics of (accounting for) land-based mitigation in a new climate agreement
}

\author{
Kate Dooley $^{1} \cdot$ Aarti Gupta $^{2}$
}

Accepted: 5 July 2016/Published online: 15 July 2016

(C) The Author(s) 2016. This article is published with open access at Springerlink.com

\begin{abstract}
This article analyzes the contested politics of including (and accounting for) land-based mitigation in a post-2020 climate agreement. Emissions from land have been only partially included to date within the United Nations Framework Convention on Climate Change and its Kyoto Protocol. The Paris Agreement, adopted in December 2015 and "applicable to all" for the post-2020 period, raises the possibility of unprecedented reliance on land-based mitigation. This has significant consequences for furthering both ambition and equity in global climate mitigation efforts. Yet, what are these consequences, and how have they manifested themselves in the existing (pre-2020) multilateral climate regime? What role do accounting rules for land-based mitigation play herein? In addressing these questions, we identify key dimensions of what we term the "governance by expertise" approach taken to land-based mitigation to date, which has served to reduce the environmental integrity of existing (developed country) mitigation efforts. Specifically, we analyze land-use accounting rules as a site of politics and highlight the "technicalization of politics" underway in this realm, which obscures the political implications of how land has been included to date. We conclude by considering whether the Paris Agreement institutionalizes similar dynamics, and the environmental integrity and equity implications of doing so.
\end{abstract}

Keywords Accounting · Climate governance $\cdot$ Equity $\cdot$ Land-based mitigation · Land-use, land-use change and forestry (LULUCF) · Negative emissions · Paris Agreement - United Nations Framework Convention on Climate Change (UNFCCC)

Aarti Gupta

aarti.gupta@wur.nl

Kate Dooley

kate.dooley@climate-energy-college.org

1 Australian-German Climate \& Energy College, and School of Geography, University of Melbourne, Parkville, Australia

2 Environmental Policy Group, Department of Social Sciences, Wageningen University, Hollandseweg 1, $6706 \mathrm{KN}$ Wageningen, The Netherlands 


\section{Introduction}

This article analyzes the contested politics of including (and accounting for) land-based mitigation in a post-2020 climate agreement. Emissions from agriculture and land-use contribute roughly a quarter of global greenhouse gas (GHG) emissions (IPCC 2014). Yet, these have been only partially included to date in the multilateral climate regime, which is centered around the United Nations Framework Convention on Climate Change (UNFCCC) and its Kyoto Protocol. Under the auspices of these agreements, countries have sought for the last two decades to agree on guiding principles and binding obligations (for developed countries) to reduce their GHG emissions.

With the newly concluded Paris Agreement under the UNFCCC, adopted in December 2015 and "applicable to all" for the post-2020 era, the partial inclusion to date of the land sector looks set to change. Key elements of the Paris Agreement raise the possibility of unprecedented reliance on land-based mitigation. This includes the temperature goal to stay "well below" a temperature increase of $2{ }^{\circ} \mathrm{C}$ and to "pursue efforts" to limit temperature increase to $1.5^{\circ} \mathrm{C}$ over pre-industrial levels (UNFCCC 2015, Article 2.1). Related to this is the long-term mitigation goal calling for a peaking of greenhouse gas emissions "as soon as possible" to be achieved through a "balance between anthropogenic emissions by sources and removals by sinks" (UNFCCC 2015, Article 4.1). The reference to "removals by sinks" implicates, inter alia, terrestrial sequestration of carbon emissions, i.e., the land sector. ${ }^{1}$

Much is at stake, given that the land sector is crucial to the pursuit of sustainable development and poverty eradication, and the most vulnerable populations depend upon land for food, fuel, and livelihoods. Added to this is the technical and political complexity inherent in monitoring land-based emissions. A key dilemma is thus how to secure landbased mitigation so as to enhance collective climate action, without undermining food security or other essential land-uses.

In this paper, we assess how the challenges of relying on land-based mitigation have been dealt with in existing (pre-2020) climate governance efforts. Our aim in doing so is to identify the consequences of pursuing similar approaches in the future. In particular, we focus on the accounting rules for the land sector developed within the UNFCCC's Kyoto Protocol, upon which a post-2020 climate regime is likely to build. We choose to focus on accounting rules because these rules have shaped the nature and scope of reliance on landbased mitigation in meeting current developed country emission reduction targets under the Kyoto Protocol. It is thus crucial and timely to understand the nature of these accounting rules, how they came to be negotiated, and their implications for ambitious and equitable pathways to future climate mitigation efforts by all.

In our paper, we view land sector accounting rules as a site of political negotiations, even as they are technically complex, obscure, and often inscrutable to those lacking requisite expertise. In analyzing the complex interplay between the technical and political in this realm, we advance the notion of "governing by expertise" in this article, which we argue has been the dominant approach to including land-based mitigation in the multilateral climate regime to date. Such an approach has entailed a technicalization of what are highly contested normative and political questions about who should do what, and how much, in combating climate change, and what role the land sector should play herein.

${ }^{1}$ Land is the only sector where $\mathrm{CO}_{2}$ is not only emitted (via forest burning and clearing and land-use change for agriculture, among other activities), but also sequestered (via photosynthesis). 
One caveat is important to note at the outset: A key conflict around land-based mitigation in the UNFCCC has centered on the scope and meaning of the term "land." While land generally refers to forests, agriculture, and other land-uses, developing countries have long opposed the inclusion of agriculture within multilateral climate mitigation efforts under the UNFCCC, given the potential adverse impacts on food security. Our analysis pertains thus to carbon-related terrestrial emissions, i.e., $\mathrm{CO}_{2}$ emissions and removals from forests, soil carbon, and cropping and grazing activities, in line with current Intergovernmental Panel on Climate Change (IPCC) reporting guidelines on so-called LULUCF (land-use, land-use change and forestry) activities. This excludes consideration of non- $\mathrm{CO}_{2}$ agricultural activities (such as livestock management and fertilizer use), which are the dominant sources of emissions from the agricultural sector.

We proceed as follows: We first distill lessons from the manner in which land-use, as understood above, has been included to date in the existing climate regime. Our discussion reveals a lack of environmental integrity in the current (accounting) approach to land sector inclusion. ${ }^{2}$ We then review the architecture of target setting in the Paris Agreement and the envisaged role (and debates around accounting) for the land sector therein. We conclude with considering the implications for ambition and equity of extending the current approach to the land sector within the post-2020 regime.

Our analysis relies upon 21 semi-structured interviews conducted during 2015 (in person during UNFCCC negotiating sessions, or by Skype and telephone) with 14 land-use negotiators (seven from developing countries and seven from developed countries), three representatives of non-governmental organizations, and four academics/experts. Interviewees were selected based on their involvement or familiarity with land-use negotiations and to reflect a range of views. All interviewees were guaranteed anonymity and hence are only identified here by broad professional affiliation and geographical region. We also draw upon our own observation of multilateral climate negotiations, from the Lima meeting in December 2014 to Paris in December 2015, as well as intersessional negotiations, encompassing six sessions. Finally, we rely on an extensive review of primary and secondary sources, including country submissions to the UNFCCC during 2014-2015 culminating in the Paris Agreement, ${ }^{3}$ grey literature, and existing academic analyses.

\section{Governing by expertise: accounting as a site of politics}

The politics of expertise, i.e., the "selective use of expert knowledge by political elites to gain support for their pre-defined policy agendas" (Fisher 1990, 28, paraphrased in Lövbrand 2009, 404-405), has been a long-standing object of critical science studies scrutiny, including in the climate domain. Lövbrand (2009) in particular has explored in detail what she terms the "links between knowledge-making and decision-making authority" in multilateral climate negotiations on terrestrial sources and sinks of greenhouse gases. Such interlinkages are now routinely analyzed within the paradigm of "co-production," which refers to a dialectical process whereby knowledge making is constitutive, insofar as it constructs particular social realities, even as a given social order shapes the nature and

\footnotetext{
${ }^{2}$ By lack of environmental integrity, we mean a discrepancy between what is accounted for, and what the atmosphere sees.

3 Specifically, we analyzed all country submissions made between January 2014 and June 2015 on "elements for a 2015 agreement" to Workstream 1 of the Ad Hoc Working Group on the Durban Platform (ADP) for references to land-use (encompassing 43 submissions).
} 
prospects of such knowledge making and its (selective) legitimation (Jasanoff 2004, see also Beck 2015; Fogel 2005).

For our purposes here, we view accounting as such a site of co-production. Viewed through a governance lens, we further conceptualize co-production as the twin processes of governing (i.e., disciplining) expertise and governing by expertise. These terms build on two much analyzed phenomena within science and technology studies: the politicization of science and the scientization of politics (Jasanoff 1998; Weingart 1999; Sarewitz 2004). The first, politicization of science, refers to the selective evoking of technical knowledge to further specific political interests and agendas, which we refer to here as governing expertise. Its mirror process, scientization (or technicalization) of politics, draws attention to how key morally charged and politically contested questions become translated into, and debated within, the potentially exclusionary, arcane, and technically impenetrable language of science, which may be accessible only to a select elite group of experts (see also Jasnoff 2003; Gupta 2011; Gupta et al. 2012).

In using "governing expertise" and "governing by expertise" to capture these two interrelated dynamics, our interest here is not only to show how politics and knowledge making are intertwined, but also to draw attention to the governance outcomes that flow from this. We do this through analyzing, inter alia, the Kyoto Protocol's LULUCF accounting rules as a site of political conflict, and how these rules have shaped the nature and scope of land-based mitigation within the UNFCCC.

\section{Negotiating land-based mitigation in the current multilateral climate regime}

This section analyzes the twin processes of governing (i.e., disciplining) expertise and governing by expertise, with regard to land-based mitigation within current multilateral climate governance. We discuss, first, the political decision taken within the UNFCCC's Kyoto Protocol to allow developed countries to include the land sector in meeting their mandatory emission reduction targets under this agreement and the associated crucial assumption of fungibility (between terrestrial and industrial emissions) accompanying this decision. We then turn to an analysis of the LULUCF accounting rules negotiated subsequent to this political decision, which impact upon the scope, scale, and manner in which land sector mitigation has been relied upon by developed countries to date.

\subsection{Governing (disciplining) expertise: agreeing on fungibility}

The Kyoto Protocol, adopted in December 1997, introduced legally binding emission reduction targets for developed countries for the first time. These targets were set for economy-wide industrial emissions, excluding the land sector. ${ }^{4}$ However, the land sector was subsequently included under the rubric of land-use, land-use change, and forestry (LULUCF) as a means through which to meet targets on the final day of negotiations in Kyoto (UNFCCC 1997). The inclusion of LULUCF was contentious from the start, given that such inclusion had the potential to weaken commitments to reduce GHG emissions from industrial sources (Fry 2002; Schlamadinger et al. 2007). Tensions arose because of the potential for some countries to meet their Kyoto targets solely or largely through claiming significant LULUCF removals, effectively offsetting emissions from the

\footnotetext{
${ }^{4}$ See Annex A to the Kyoto Protocol.
} 
industrial sector and thus relieving these countries of the need to substantially reduce industrial emissions (Lövbrand 2004).

This was evident, for example, from arguments made by some members of the so-called Umbrella Group of countries, who called for comprehensive inclusion of LULUCF. ${ }^{5}$ As one interviewee involved in the Kyoto negotiations noted, "the Chair was told by Umbrella Group countries (US, Canada, Norway, Russia, Iceland), that there is no way we will agree [to the Kyoto Protocol] unless we can credit some land use activities." 6 The Alliance of Small Island States (AOSIS), in particular the Marshall Islands and Barbados, as well as Costa Rica and Brazil, preferred to limit reliance on terrestrial sinks or exclude them altogether (Earth Negotiations Bulletin 1997), while the European Union (EU) remained internally divided over the issue. ${ }^{7}$

While the details of these dynamics have been analyzed elsewhere (e.g., Fogel 2005; Fry 2002, 2007), we draw attention to two aspects below: the assumption of fungibility that underpins use of LULUCF to meet developed country Kyoto targets, which entailed a disciplining of scientific knowledge, and offset mechanisms negotiated under the UNFCCC and Kyoto, which also assume fungibility and implicate the land sector in developing countries as well.

\subsubsection{Fungibility between terrestrial and industrial emissions}

The conflicts over inclusion of LULUCF in the Kyoto Protocol were due in part to abiding contestations over the assumption of fungibility, i.e., the assumption that avoided emissions and removals from the land sector were interchangeable with emission reductions from fossil fuels. This assumption remained singularly contested. Brazil, for example, "wanted LULUCF completely out of Kyoto, raising all of the legitimate scientific questions about this. They didn't want any kind of cheating which was related to the accounting. In principle they thought [Kyoto] should be an energy convention, making it also about forests made it much more complicated." 8 This was also because, if included in the Kyoto Protocol, special accounting rules would be needed for LULUCF, given the unique complexities of the sector that prevented easy comparison between fossil and terrestrial emissions. As we noted earlier, land is the only sector where $\mathrm{CO}_{2}$ is not only emitted (via forest burning and clearing and land-use change for agriculture, among other activities), but also sequestered (via photosynthesis). As such, there were a wide variety of political positions articulated at this time on why and how the land sector was different, and thus how valid the assumption of fungibility was. ${ }^{9}$

Fungibility was simultaneously much debated in scientific circles and continues to be. While some see it as unproblematic (e.g., Estrada et al. 2014; Lee et al. 2015; Parker et al. 2014), others outline key technical barriers to comparability between land and fossil

\footnotetext{
5 The Umbrella Group is a negotiating bloc of non-EU developed countries. During Kyoto negotiations, it consisted of Australia, Canada, Iceland, Japan, New Zealand, Norway, the Russian Federation, Ukraine, and USA. Japan initially opposed inclusion of sinks, but later agreed, when under pressure to take on a higher emission reduction target (Interview with developing country negotiator, Bonn, Germany, June 9, 2015).

${ }^{6}$ Interview with developing country negotiator, Bonn, Germany, June 9, 2015.

7 Ibid.

${ }^{8}$ Developing country negotiator, Bonn, June 9, 2015.

9 Interviews with five developed country and seven developing country negotiators, as well as two LULUCF experts, conducted in person in Bonn, Germany, in June and October; and in Paris, France in December; and via telephone between July and October, 2015.
} 
emissions, including inter alia, high levels of uncertainty in monitoring land-based emissions; difficulties in distinguishing between anthropogenic and natural causes of land-based emissions and removals; and non-permanence of removals (Fry 2002; Hansen et al. 2013; Mackey et al. 2013; Powlson et al. 2011).

For example, with regard to non-permanence of soil carbon sequestration, Powlson et al. have expressed concern that "the possibilities for climate change mitigation by this means may be exaggerated... even though these limitations have been clearly enunciated in numerous publications" (2011, 43-52). Fry $(2002,162)$ has observed that the early LULUCF discussions "lacked a critical analysis of the efficacy of sinks projects, despite the fact that..., there were a number of scientific articles questioning the efficacy of LULUCF activities." The sustained scientific critique and persisting debates around the efficacy and mitigation potential of terrestrial sinks ultimately did not impede the inclusion of LULUCF in the Kyoto Protocol, indicating that sequestration science (i.e., the science of removing emissions through terrestrial sinks) was selectively evoked by policy experts in this realm to align knowledge with a politically desired outcome - the use of sinks in climate mitigation.

\subsubsection{Offsetting}

The political decision to assume fungibility between terrestrial and industrial emissions also laid the basis for including land-based mitigation in developing countries within the parameters of the Kyoto Protocol. This was achieved through the Clean Development Mechanism (CDM) of the Kyoto Protocol, which allowed developed countries to partially meet their Kyoto targets by purchasing credits generated from emission reduction projects in developing countries (i.e., offsetting ongoing emissions in one place with reductions in another). Reliance on land-based mitigation was more limited in the CDM than under LULUCF, largely due to the sheer scale of potential credits the unrestricted inclusion of land could yield (given higher deforestation rates, and greater land areas in developing countries). Hence, "avoided deforestation" as an offsetting activity was excluded from the $\mathrm{CDM}$ all together, and reliance on terrestrial sinks was limited to the specific activities of afforestation and reforestation, and capped at $1 \%$ of Kyoto targets annually (Höhne et al. 2007). This followed particular opposition to the inclusion of avoided deforestation as a crediting activity in the CDM, with Brazil, China and AOSIS raising concerns about the potential for such credits to offset an increase in developed country (industrial) emissions (Fry 2007). ${ }^{10}$

In 2005, a new proposal was made within the UNFCCC to incentivize avoided deforestation in developing countries (thus far excluded from the CDM). Established as a voluntary mechanism, whereby developing countries could receive financial incentives to reduce emissions from forest loss and enhance sequestration, REDD+ ${ }^{11}$ has now been included in the Paris Agreement as a results-based payment mechanism (UNFCCC 2015, Article 5.2). Furthermore, despite current lack of clarity regarding who (the host or donor country) can credit any resultant emission reductions, REDD+ accounting rules have been developed to potentially enable REDD+ credits to be used as offsets by purchasing

\footnotetext{
10 This point was also made in an author interview with developing country negotiator, Bonn, Germany, June 9, 2015.

11 REDD + refers to the agreed eligible activities in developing countries, which are: reducing emissions from deforestation and forest degradation; conservation of forest carbon stocks; sustainable management of forests; and enhancement of forest carbon stocks.
} 
countries or entities. This possibility has led to contentious debates within the UNFCCC over the stringency of verification required for REDD+ results (Dutschke 2013), with many developing country negotiators noting that REDD + accounting rules are stricter than those that developed countries adhere to in crediting their own LULUCF activities. ${ }^{12}$

Limiting terrestrial sinks in the CDM and developing strict accounting rules for REDD+ can be seen as political compromises in response to concerns expressed by the EU and AOSIS, among others, over both the environmental integrity and social impacts of land-based offset projects in developing countries (Fry 2002), even as the scientific debate over fungibility has remained unchanged.

These political decisions on including land-based mitigation in the climate regime, accompanied by a selective evoking (or ignoring) of scientific disputes over fungibility, shaped negotiation of LULUCF accounting rules, to which we turn next.

\subsection{Governing by expertise: accounting rules and a technicalization of politics}

Once the Kyoto Protocol was agreed, along with the assumption of fungibility between terrestrial and industrial emissions, negotiations began on developing accounting rules for the land-use sector within the UNFCCC's Subsidiary Body for Science and Technological Advice (SBSTA). This technical negotiating site saw LULUCF negotiators employing complex scientific arguments about the intricacies of accounting for terrestrial emissions and removals, yet doing so in a way that suited their specific circumstances, i.e., the varying potentials in different countries for relying on land-based mitigation in meeting Kyoto targets. $^{13}$

In analyzing these dynamics here, we review below the contested negotiations around, first, the scope and scale of permitted land-based mitigation and, second, baselines and reference levels against which to account for land-based mitigation. ${ }^{14}$

\subsubsection{Scope and scale}

Scope (i.e., which land-use activities were to be included) and scale (i.e., limits on landbased mitigation) quickly became among the most divisive issues in negotiating LULUCF accounting rules (Höhne et al. 2007; Schlamadinger et al. 2007). The Umbrella Group (in particular Canada and the USA) with large forest areas wanted a broad scope and no limits on using LULUCF to offset industrial emissions. China and the G-77, as well as AOSIS, opposed this position. ${ }^{15}$

The political compromise reached was to develop an accounting innovation: the $a c$ tivity-based approach to LULUCF accounting, i.e., accounting for specific land-related activities, rather than land areas. A widely asserted technical reason for this was to help distinguish between anthropogenic (i.e., managed) terrestrial emissions and removals from

\footnotetext{
12 Several interviewees from developing countries made the point that REDD + accounting and safeguard rules are stricter than LULUCF rules for developed countries. Interviews conducted in Bonn, Germany, June 9 and 11, and via telephone November 21, 2015.

13 Author interviews with several developing country negotiators, in Bonn, Germany, June 9, 11, and October 21, 2015. See also Fry (2007) and Lövbrand (2009).

14 An exhaustive account of all land-use accounting rules is beyond the scope of this paper. For comprehensive discussion of land-use rules see also, e.g., Estrada et al. (2014), Höhne et al. (2007), Iversen et al. (2014), Parker et al. (2014), Schlamadinger et al. (2007).

15 Interview with developing country negotiator, Bonn, Germany, June 9, 2015.
} 
natural carbon fluxes. Once an activity-based approach was selected, however, another key axis of conflict became whether all land-related activities were to be mandatory or whether countries could choose which ones (if any) to rely upon in meeting their Kyoto targets. Countries negotiated extensively on this, with the political implications of these choices obscured by technically complex discussions of GHG fluxes associated with each designated activity. Eventually, only the activities of forest clearing and forest planting (since 1990) were declared to be mandatory to account for. Countries could choose whether or not to account for other land-use activities, including forest management, which is potentially a large source of both emissions and removals (Ecosystems Climate Alliance 2009).

While some existing analyses of this negotiated division between mandatory and voluntary activities for LULUCF accounting emphasize the technical rationales underpinning them (e.g., Höhne et al. 2007; Schlamadinger et al. 2007), others point to the political contestations underlying these decisions (e.g., Fry 2002, and Lövbrand 2009). In particular, the decision to characterize forest management as a voluntary activity became one of the most heavily criticized aspects of LULUCF accounting rules in the Kyoto Protocol's first commitment period (2008-2012), given significant under-reporting of forest-related emissions that became possible as a result (for details, see Daviet and Goers 2009).

In addition to deciding on which activities to include, LULUCF accounting rules also addressed limits on the use of terrestrial sources and sinks (i.e., the scale of permitted inclusion). As one developing country negotiator put it, "If you set the bar too high (i.e., with strict limits on inclusion), (countries) will not participate and you get nothing. If the bar is too low, you do not reduce emissions. It is very hard to balance." ${ }^{16}$ The key concern was that in the absence of limits, the scale of land sector emissions and removals could outweigh efforts to reduce industrial emissions (Höhne et al. 2007). While this was widely recognized, the withdrawal of the USA from the Kyoto Protocol in 2001 ironically strengthened the hand of other Umbrella Group countries in securing more widespread reliance on land-based mitigation within Kyoto, given the need to keep these countries on board (Fry 2002; Lövbrand 2009).

With the discussion on scale and limits remaining heated, the EU eventually called for caps ("allowable limits") on LULUCF use by each Kyoto Party, as a compromise. As one developed country negotiator put it, "When you're really uncertain [about your accounting rules] the political solution is to put a cap." ${ }^{17}$ While AOSIS countries demanded an indepth scientific analysis of proposed caps, given the collective potential of such caps to meet more than half the Kyoto Protocol's overall emission reduction target (den Elzen and Lucas 2003; cited in Höhne et al. 2007), political expediency saw little such analysis. The compromise reached was for countries to politically negotiate their own cap on LULUCF, which had the effect of generating substantial credits that countries could use in meeting their Kyoto targets.

\subsubsection{Baselines and reference levels}

How negotiation of LULUCF accounting rules serves as a site of political conflict was also evident in debates around the baselines against which to assess terrestrial emissions and removals in a given period. Agreeing on baselines is substantially more complex for the land sector than it is for industrial emissions, given that land is the only sector with emissions as well as removals. Industrial emission reductions are straightforwardly

\footnotetext{
16 Interview with developed country negotiator, Bonn, Germany, June 10, 2015.

17 Interview with developed country negotiator, Bonn, Germany, June 6, 2015.
} 
assessed through a gross-gross baseline approach, wherein emissions in a base year are compared with emissions in the reporting period (Rocha et al. 2015). However, inclusion of emissions and removals in the same accounting framework requires, logically, a net-net approach. ${ }^{18}$ A net-net approach, i.e., comparing emissions minus removals in the base year against emissions minus removals in the reporting period, would maintain the symmetry of the gross-gross approach (Rocha et al. 2015; Schlamadinger et al. 2007). While scientifically tenable, the political challenge of using a net-net approach, however, is that any increase in emissions from the land sector in the reporting period would make targets more difficult to meet. ${ }^{19}$ This possibility is exacerbated by the fact that forest management decisions of the past determine whether managed forests are a net source or a net sink during any given period (referred to as legacy effects), leading to most countries with Kyoto targets refusing to accept a net-net accounting approach. ${ }^{20}$

Given this opposition to net-net accounting, a much more complex approach to baselines for the land sector was negotiated: the "gross-net" accounting approach. This does not include emissions and removals from forest-related activities in the baseline, which reflects only industrial emissions, but does allow for both industrial and (selected) forestrelated activities to be accounted for during the subsequent reporting and commitment period (Iversen et al. 2014). The gross-net approach is favoured by those countries with an overall forest sink (i.e., where terrestrial removals are higher than terrestrial emissions in a commitment period), making overall targets easier to meet. As a result, it has been criticized for permitting unearned or "windfall" credits (Daviet and Goers 2009; Rocha et al. 2015) for such countries.

The gross-net approach was, however, not supported by countries where the forest sector is an overall source of emissions (i.e., where emissions from deforestation are higher than removals through forest planting), given that these emissions would then be added to overall targets, making them harder to meet (Rocha et al. 2015). As one negotiator put it, “...if you have any kind of rule which is just-deforestation is really bad, you have to debit it - then straight away any country with high deforestation is going to have very high emissions under that accounting framework." ${ }^{21}$ However, very few developed countries have high deforestation rates (Australia being a notable exception ${ }^{22}$ ), making the decision to have a gross-net LULUCF accounting approach for Kyoto politically feasible. It proved, furthermore, to be a boon for those countries (including in the EU) with low deforestation rates but with intensive forest management, given that forest management was a voluntary activity that could be excluded from consideration in meeting first commitment period Kyoto targets.

The contested process of negotiating politically palatable (but also scientifically defensible) baselines continued for the second commitment period of the Kyoto Protocol (2013-2019). One key change was that forest management became a mandatory activity

\footnotetext{
18 This point was made in several interviews, including with a developed country negotiator, Bonn, Germany, June 11, a LULUCF policy expert via telephone June 16, and an NGO representative in Paris, France December 9, 2015.

${ }^{19}$ Interview with developed country negotiator, Bonn, Germany, June 11, 2015.

${ }^{20}$ However, a net-net approach is accepted for cropland and grazing lands, where carbon stocks can be affected in short time periods through management practices (Schlamadinger et al. 2007).

21 Interview with developed country negotiator, Bonn, Germany, June 11, 2015.

22 As a result, Australia negotiated a special clause in the Kyoto Protocol (Article 3.7), allowing it to apply net-net accounting to deforestation (otherwise only applied to cropland and grazing land management), resulting in significant windfall credits as deforestation rates dropped from historical highs (Macintosh 2011).
} 
for the Kyoto second commitment period, following intense NGO lobbying to close "LULUCF loopholes." ${ }^{23}$ With this, however, the EU, together with some Umbrella Group countries, insisted on revisiting the gross-net baseline accounting approach for the specific activity of forest management in the Kyoto second commitment period, once it became mandatory to include.

With the flexibility to exclude this activity now removed, and the accounting benefits that this flexibility had earlier conferred now gone, the EU called for forest management not to be subject to a gross-net baseline, but rather for development of a so-called Forest Management Reference Level (FMRL) (Iversen et al. 2014 ${ }^{24}$ ). The use of reference levels is another unique accounting innovation in this context, developed as a political compromise between those trying to improve the credibility of accounting rules and those wanting to maintain flexibility in use of LULUCF to meet targets.

The FMRL means that instead of a baseline against which to judge performance in a given period, countries can propose a quantified (expected) future level of performance (in terms of net emissions from forest management) and compare this against actual emissions at the end of a commitment period (Rocha et al. 2015). Known as a "projected reference level," the FMRL was seen by the EU as crucial to avoid the problems of legacy effects associated with forest management, but was also subject to a cap to avoid excessive credits. However, any use of reference levels opens up the possibility of inflating future expectations of emissions, in order to make targets easier to meet. As one developed country negotiator put it, "The projected reference level is the most politically feasible [accounting approach] to agree on, there are problems with it, but the alternatives also have problems. [It is] used for political agreement." 25

It is also important to note here, in concluding, that the REDD+ mechanism also relies on reference levels (rather than baselines) in assessing performance, allowing countries to set business-as-usual (BAU) expectations for increases in deforestation and to receive credits for any improvement against these BAU expectations. The credibility of the reference level approach is heavily reliant on technical review (Briner and Konrad 2014). Yet reviews remain fraught with challenges, given extensive scientific uncertainties and varying political expectations. Analysis has shown that the level of credits from LULUCF varies widely depending on plausible interpretations of accounting rules (Böttcher and Graichen 2015).

The discussion above shows how the inclusion of land-use to date in the multilateral climate regime reflects politically negotiated compromises, despite the ostensibly technical character of LULUCF accounting rules. One dominant response to perceived LULUCF "loopholes" has been to advocate improved rules and increased ambition through ensuring that negotiations are "based on sound science," with greater reliance on data sets to assess the impact of various options (Höhne et al. 2007, 354). Yet, the reality that "LULUCF is a negotiated system that tries to work around competing national interests" 26 goes against the notion that "sound" science-based rules, seen as credible by all on the basis of their

\footnotetext{
${ }^{23}$ From interview with NGO representative, Paris, France, December 8, 2015.

${ }^{24}$ Iversen et al. point to the mandatory inclusion of forest management as one of the reasons behind the FMRL; interviews with country negotiations in Bonn, Germany, June 9 and October 21, as well as an NGO representative in Paris, France, December 9, also raise this issue.

25 Interview with developed country negotiator, Bonn, Germany, June 6, 2015.

${ }^{26}$ Interview with developed country negotiator, Bonn, Germany, June 6, 2015.
} 
technical merits, can be devised. As one negotiator put it, "there is no perfect rule-what seems fair to one is an extra burden for another."27

As several interviewees have also noted, however, country-specific data on land-use emissions have improved as a result of requirements for LULUCF accounting, with one land-use expert adding that "except in a few countries, fears of LULUCF credits swamping Kyoto targets did not materialise." 28 This notwithstanding, our discussion highlights how LULUCF was introduced into the Kyoto Protocol to make developed country emission reduction targets easier to meet. Through political negotiations and compromise, complex accounting rules were designed to both permit and limit the degree to which terrestrial sinks could be used to offset industrial emissions.

In a post-2020 climate regime, where land is expected to play a more prominent role, any approach to mitigation that focuses on "net" emissions (i.e., emissions minus removals), while obscuring the politics hidden in land-use accounting, runs the risk of not delivering the required ambition and potentially exacerbating inequitable burden sharing. We turn to these issues next.

\section{Negotiating land-based mitigation in the Paris Agreement}

The architecture of the post-2020 climate regime differs from that of the Kyoto Protocol. In contrast to having multilaterally negotiated emission reduction targets for countries, the overall ambition level is agreed multilaterally in the Paris Agreement through the temperature goal (Article 2.1) and the long-term mitigation goal (Article 4.1) (UNFCCC 2015). In seeking to further these goals, the Paris Agreement institutionalizes two key elements: a bottom-up process whereby each country develops its own "nationally determined contributions" (NDCs) to meeting these aggregate goals, which may include land-based mitigation, and a multilaterally agreed "transparency framework" 29 through which to account for, and report on, the progress that countries are making toward implementing their NDCs.

As in the previous section, we proceed here by first analyzing the dynamics of governing (i.e., disciplining) expertise that might be discernible in how the land sector is implicated in the Paris Agreement, with a focus on the long-term mitigation goal. Second, we consider the current state of debate regarding accounting for land-based mitigation in the Paris Agreement. Here, we touch briefly upon divergent views over whether a common accounting framework is required for all countries and associated debates over whether such a common framework requires countries to take on quantified targets, including for the land sector. Through doing so, we illustrate the implications of continuing to rely on a "governing by expertise" approach to land-based mitigation (and its accounting rules) in the post-2020 era.

\footnotetext{
$\overline{27}$ Interview with developed country negotiator via telephone, October 13, 2015.

28 Interview with LULUCF expert via telephone on June 21, 2015. Other interviews, with a developed country negotiator in Bonn, Germany, June 10, and a LULUCF expert in Paris, France, December 11, also made this point.

${ }^{29}$ In our discussions below, we focus on accounting issues, rather than on the broader negotiations around a (common) transparency framework in a new agreement. For an analysis of the contested geopolitics of transparency in global climate governance, see Gupta and Mason (2016).
} 


\subsection{Governing (disciplining) expertise: land-use and the long-term mitigation goal}

Analyzing the prospects for a disciplining of expertise in the manner in which land is implicated in the Paris Agreement requires consideration of the long-term mitigation goal articulated within it. Negotiations on language to capture aggregate mitigation ambition were long and intense, in the lead up to finalization of the agreement in Paris. Terminology such as "net-zero emissions," "near zero," carbon or climate neutrality, and decarbonization all appeared in the draft text during the course of the negotiations. A mitigation goal of "net-zero" emissions was particularly contentious, with some seeing this as a straightforward scientific statement on an approach to stabilizing atmospheric GHG emissions, ${ }^{30}$ while others viewed it as a political license to "offset industrial emissions with land-based sinks." 31

The net-zero language was introduced to the UNFCCC discussions after the Intergovernmental Panel on Climate Change (IPCC) Fifth Assessment Report included long-term mitigation pathways that relied heavily on assumptions of "negative emissions" (meaning the removal of carbon from the atmosphere via terrestrial sinks, often combined with geological storage) (IPCC 2014). It was first raised during the Lima climate meeting in December 2014, where New Zealand suggested a mitigation goal of "net-zero $\mathrm{CO}_{2}$ emissions by 2100 in line with the latest science." ${ }^{32}$ Such a position received vocal support from Switzerland, ${ }^{33}$ but Brazil noted that by ascribing "the latest science" a legal role in the official text "we might be creating some politicization." ${ }^{34}$ Bolivia, Argentina, and Ecuador opposed the use of "net-zero" on the grounds that it introduced a new concept that did not appear in the Framework Convention, or in related decisions. ${ }^{35}$ Norway and the EU supported the terms carbon or climate neutrality, ${ }^{36}$ and the USA preferred "decarbonisation of the global economy" (Ajit 2015a).

With no consensus emerging, the ambiguous language that became the long-term mitigation goal in the Paris Agreement calls for a "peaking of greenhouse gas emissions... as soon as possible" (i.e., without identifying a specific time frame, or a specific limit on emissions) to be achieved through "a balance between anthropogenic emissions by sources and removals by sinks" (UNFCCC 2015, Article 4.1). The term "removals by sinks" leaves open the possibility of continuing industrial and terrestrial emissions, as long as these are (ostensibly) being offset by enhancement of sinks.

It is important to note here that the wording of this long-term mitigation goal is very close to the contentiously negotiated paragraph on inclusion of land-use in the Kyoto Protocol, which refers to "net changes in greenhouse gas emissions by sources and removals by sinks" (UNFCCC 1997, Article 3.3, italics added). A key difference is that the Kyoto Protocol defines the use of sinks as "limited to afforestation, reforestation and

\footnotetext{
30 Author interview with LULUCF expert, Paris, France, December 8, 2015.

31 Interview with NGO representative, Bonn, Germany, October 20, 2015.

32 Author personal observation, COP 21 Lima, December 6, 2014.

33 Author personal observation, Geneva, February 8, 2015.

34 Ibid.

35 These points were raised frequently by these countries and were observed during open meetings on the long-term goal during the September 2015 negotiating session in Bonn, Germany.

36 The position of the EU and Norway on the long-term goal changed throughout the year, from supporting net-zero in the Bonn September session to calling for carbon and climate neutrality during the Paris negotiations, as an alternative to the opposition from developing countries on net-zero (author observations; see also Ajit 2015a).
} 
deforestation since 1990" (UNFCCC 1997, Article 3.3), which circumscribes and limits the activities that qualify as "removals by sinks." A second key difference is placement and context. Article 4.1 in the Paris Agreement is the collective long-term mitigation goal, while the mitigation goal in the Kyoto Protocol reads, "Parties shall limit the emissions of the greenhouse gases listed in Annex A" (which refers to energy and industrial emissions, excluding terrestrial emissions) to "not exceed their assigned amounts" (UNFCCC 1997, Article 3.1), thus, with a clear focus on reducing emissions from fossil fuel use.

Reliance on land-based mitigation in the Kyoto Protocol was introduced after targets for industrial emission reductions were set (as discussed in Sect. 3), and was limited from the start (although the precise nature of these limits remained the subject of political debates). In the Paris Agreement, on the other hand, land-based sinks have moved from being a politically contested add-on to occupying center stage in the long-term mitigation goal, as laid down in Article 4.1.

But why exactly does Article 4.1 of the Paris Agreement implicate land, and to what extent might this reflect a governing (or disciplining) of expertise, with implications for environmental integrity and ambition? "Balancing emissions and removals" effectively means the same as "net-zero emissions," carbon neutrality, and similar terminology (Levin et al. 2015), which all imply that terrestrial sinks are both fungible with, and will be used to offset, ongoing (industrial and terrestrial) emissions (Schaeffer et al. 2013).

So while a goal that essentially puts the world on a pathway toward net-zero global emissions appears ambitious, Article 4.1 says nothing about the scale of reliance on landbased mitigation that would be required to meet this global mitigation goal, nor the speed and timing of a concurrent reduction in fossil fuel use, hence obscuring political questions around when, how and by whom emissions are reduced. Going beyond this, and of direct relevance to the governing (disciplining) of expertise, the varied scientific uncertainties and contestations around the sequestration potential and permanence of terrestrial sinks, as debated during the Kyoto period, remain salient for the Paris Agreement, leaving open the prospect that scientific expertise will (continue to be) selectively evoked in justifying specific efforts at "balancing emissions and removals" in the decades to come.

\subsection{Governing by expertise: technicalizing (politics of) land-use accounting?}

With the land sector set to play a crucial and open-ended role in future climate mitigation under the Paris Agreement, a politically charged question is how accounting for this sector will occur in the post-2020 climate mitigation era, whether a common accounting framework is required for all countries, and if this requires countries to take on quantified targets, including for the land sector. These debates are linked in turn to overarching conflicts over differentiation in obligations between developed and developing countries, in an agreement that is "applicable to all."

During negotiation of the Paris Agreement, the EU and the USA took the position that the purpose of a common accounting framework was to permit comparability, which in turn required quantified targets (Ajit 2015b). Whether all countries should provide quantified targets thus became, and remains, a particularly contentious issue, tied up with fundamental conflicts over whether inclusion of the land sector in NDCs is to be voluntary or mandatory and also whether the land sector can be included in any new market mechanisms (established via Article 6 of the Paris Agreement).

Throughout the negotiations, countries proposed a variety of approaches to mitigation commitments, ranging from quantified economy-wide emission reduction targets (e.g., 
$\mathrm{EU}^{37}$ Switzerland, ${ }^{38}$ Norway $\left.{ }^{39}\right)$; a diversity of mitigation actions for developing countries, including emissions intensity targets $\left(\mathrm{China}^{40}\right)$; and commitments to qualitative policies and measures $\left(\mathrm{Nepal}^{41}\right)$. This debate has particular relevance for the land sector, due to the difficulty of quantifying land sector emissions and the complexity of including these in an accounting framework that includes industrial emissions, as discussed in Sect. $3{ }^{42}$

The Paris Agreement leaves discussions of a (common) accounting framework and specific rules for land-use accounting, to future negotiations. ${ }^{43} \mathrm{We}$ provide here (in Table 1) a brief overview of a few intended ${ }^{44}$ NDCs (INDCs) proposed by countries in the lead up to the Paris meeting, in order to reveal the diversity of approaches currently being adopted to land-use (and land-use accounting) in the context of the Paris Agreement, and to the scope and scale of such inclusion. ${ }^{45}$

Table 1 provides a glimpse into the political conflicts that are likely to come to the fore in determining (and accounting for) the contribution of the land sector to countries' mitigation commitments. As a developed country negotiator noted about the politically contested nature of land sector accounting, “...in the context of a new agreement, capacities of countries are more diverse, so this adds more complexity to the idea of a common framework [for land-based mitigation]. It is difficult to find common accounting rules that suit all... sinks have evolved differently in different countries, leading to fighting over accounting rules to suit national circumstances." 46

The diversity of country circumstances in the land sector also complicates the idea of comparability of effort. A recent comprehensive assessment of countries' INDCs by Grassi and Dentener (2015) indicates a potential LULUCF mitigation contribution of 20-25\%, relative to other sectors, by 2030 . This implies that the land sector is expected to be a significant component of mitigation efforts in the future, even as the authors note large uncertainties in these estimates "due to countries projections and accounting rules" (Grassi and Dentener 2015, 13, italics in original). The INDC Synthesis Report, produced by the UNFCCC Secretariat, further adds that "several of the INDCs do not provide comprehensive information on the assumptions and methods applied in relation to LULUCF, which presents a major challenge for the quantitative evaluation of the aggregate effect of the INDCs" (UNFCCC 2016, 6).

37 The Ad Hoc Working Group on the Durban Platform for Enhanced Action (ADP): the 2015 Agreement. Submission by Italy and the European Commission on behalf of the European Union and its Member States. Rome, October 14, 2014.

38 Elements of the 2015 Agreement: Switzerland's views, March 4, 2014.

39 Norway submission to the ADP, March 6, 2014.

40 Views and proposals on the work of the Ad Hoc Working Group on the Durban Platform for Enhanced Action. Submission by Nepal on behalf of the Least Developed Countries Group, March 17, 2014.

41 China's submission on the work of the Ad hoc Working Group on Durban Platform, March 6, 2014.

42 Multiple interviewees emphasized capacity constraints facing developing countries, including three developed and seven developing country negotiators, one policy advisor, and one NGO representative, interviews undertaken in Bonn, Germany, June 6-11; by telephone July-October, and in Paris, France, December 11, 2015.

43 Paragraphs 31, 37, 38 of Decision 1/CP.21 contain mandates for further negotiations to develop accounting rules (UNFCCC 2015).

44 In 2015, countries submitted intended NDCs, which are expected to become NDCs when the Paris Agreement enters into force in 2020.

45 It is outside the scope of this paper to analyze all submitted INDCs; our discussion here is illustrative, rather than comprehensive.

46 Interview with developed country negotiator, Bonn, Germany, June 10, 2015. 
Table 1 Overview of land-use inclusion in selected INDCs

\begin{tabular}{|c|c|c|c|}
\hline Country & Mitigation commitment & Land-use inclusion & Observations \\
\hline Australia & $\begin{array}{l}26-28 \% \text { below } 2005 \text { by } \\
2030\end{array}$ & $\begin{array}{l}\text { Included in economy-wide } \\
\text { target. Net-net } \\
\text { accounting based on } \\
\text { inventory reporting }\end{array}$ & $\begin{array}{l}\text { IPCC guidance for natural } \\
\text { disturbance and variation }\end{array}$ \\
\hline $\mathrm{EU}$ & $\begin{array}{l}\text { At least } 40 \% \text { below } 1990 \text { by } \\
2030\end{array}$ & $\begin{array}{l}\text { Included in economy-wide } \\
\text { target, but accounting } \\
\text { rules are yet to be } \\
\text { established }\end{array}$ & $\begin{array}{l}\text { Inclusion of LULUCF may } \\
\text { weaken } 40 \% \text { target, depending } \\
\text { on accounting rules used }\end{array}$ \\
\hline Mexico & $\begin{array}{l}\text { Unconditional target of } \\
25 \% \text { (conditional pledge } \\
\text { of up to } 40 \% \text { ) below BAU } \\
\text { by } 2030\end{array}$ & $\begin{array}{l}0 \% \text { deforestation by } 2030 \\
\text { included as an adaptation } \\
\text { measure }\end{array}$ & $\begin{array}{l}\text { Conditional pledge will require } \\
\text { market mechanisms; no } \\
\text { reference to accounting rules }\end{array}$ \\
\hline $\begin{array}{l}\text { New } \\
\text { Zealand }\end{array}$ & $30 \%$ below 2005 by 2030 & $\begin{array}{l}\text { Included in economy-wide } \\
\text { target and will build on } \\
\text { Kyoto Protocol rules }\end{array}$ & $\begin{array}{l}\text { Provisional target pending } \\
\text { approaches taken to land sector } \\
\text { accounting and access to } \\
\text { carbon markets }\end{array}$ \\
\hline Norway & $40 \%$ below 1990 by 2030 & $\begin{array}{l}\text { Included in economy-wide } \\
\text { target, but accounting } \\
\text { rules dependent on EU } \\
\text { decisions }\end{array}$ & $\begin{array}{l}\text { Inclusion of land sector and } \\
\text { subsequent accounting rules } \\
\text { shall not reduce } 40 \% \text { target }\end{array}$ \\
\hline Russia & $\begin{array}{l}25-30 \% \text { below } 1990 \text { by } \\
2030\end{array}$ & $\begin{array}{l}\text { Included in economy-wide } \\
\text { target }\end{array}$ & $\begin{array}{l}\text { Significant uncertainty around } \\
\text { accounting assumptions for } \\
\text { land-use sink }\end{array}$ \\
\hline US & $\begin{array}{l}26-28 \% \text { below } 2005 \text { by } \\
2025\end{array}$ & $\begin{array}{l}\text { Net-net accounting for land } \\
\text { sector }\end{array}$ & $\begin{array}{l}\text { Notes methodological challenges } \\
\text { to estimating emissions in land } \\
\text { sector }\end{array}$ \\
\hline
\end{tabular}

Based on author analysis of selected INDCs submitted in 2015 that included the land sector

The diversity of country circumstances and approaches, as demonstrated in INDCs, points to the difficulty of having a common accounting framework for the land sector, which is highlighted in the politics of deciding upon baselines or reference levels for terrestrial emissions. Some countries argue that common accounting rules for all would be feasible, including for the land sector, as long as flexibility exists to set land-based mitigation reference levels appropriate to national circumstances. ${ }^{47}$ As one developed country LULUCF negotiator pointed out, "the key point is having the flexibility to set appropriate baselines, and I think a lot of developing countries don't realize that [by doing so] they could bring their whole land sector in and set baselines that create an expectation of zero debits, zero credits." ${ }^{48}$ This implies, however, that flexible accounting rules might come to be seen as a means for countries to report net-zero emissions, rather than as a means by which to facilitate emission reductions. While flexibility in the setting of reference levels and/or baselines (to accommodate whether land is a net source or net sink of emissions for a given country at any given period of time) would be a politically plausible way for developed and developing countries, with radically different land-use scenarios, to agree to common accounting rules for the land sector, such an approach would obscure real emissions from this sector.

\footnotetext{
47 Interview with developed country negotiator, Bonn, Germany, June 11, 2015.

48 Ibid.
} 
More generally, this highlights the inadequacy of a "governing by expertise" approach to addressing the social and political questions inherent in the role of land in moving toward a zero-carbon future. Rather than technicalizing what are fundamentally political conflicts, future discussions on the scale, scope, and accounting approaches to land-based mitigation face the challenge of how to reveal and engage with, rather than obscure, the political choices and trade-offs therein.

\section{Conclusion: breaking new ground or allowing history to repeat?}

In the recently negotiated Paris Agreement, land-based mitigation has moved from an earlier marginal and contested role in multilateral climate politics to center stage. This is in large part due to the assumed reliance on "negative emissions" in the second half of the century, introduced into the debate through IPCC mitigation scenarios (IPCC 2014) and now implicated in the long-term mitigation goal. As we have shown here, (over)-reliance on land-based sinks could have far-reaching political consequences, given the likely distributional impacts of land-based mitigation, and concerns over fungibility in using terrestrial sinks to offset industrial emissions. Furthermore, accounting rules for the land sector remain a crucial site wherein the level of ambition in the new agreement, and allocation of responsibility and burden sharing among countries, will be negotiated.

The current state of play on these issues is that the Paris Agreement sets no direct limits on "balancing" emissions with removals, although it does say that the "balancing" must be done "on the basis of equity," and "in the context of sustainable development and poverty eradication" (UNFCCC 2015, Article 4.1). This notwithstanding, in a context where removals via terrestrial sinks are expected to make a significant contribution to achieving the long-term mitigation goal, this implies a need for land to shift, eventually, from being a net source globally to a net sink. Yet the distributional consequences of this remain crucial to analyze, with existing models "universal[ly] projecting that the majority of agriculture and forestry mitigation, and bioenergy primary energy, will occur in developing and transitional economies" (IPCC 2014, 68). With this in mind, our analysis reveals the need for a more open political debate over diverse mitigation pathways and their implications over the course of the century, one which takes into account the social and environmental limits to land-based mitigation. Negotiating limits to land-based mitigation that consider not only the technical, but also the political, socioeconomic and equity aspects is necessary, in determining how much, where, and what type of land-based abatement can reasonably be relied upon for climate mitigation.

Open Access This article is distributed under the terms of the Creative Commons Attribution 4.0 International License (http://creativecommons.org/licenses/by/4.0/), which permits unrestricted use, distribution, and reproduction in any medium, provided you give appropriate credit to the original author(s) and the source, provide a link to the Creative Commons license, and indicate if changes were made.

\section{References}

Ajit, T. (2015a). Debate behind closed doors on the temperature goal in the Paris agreement, Paris News Update \#19. Penang: Third World Network.

Ajit, T. (2015b). Differentiation under the Paris Agreement-A tough fight, Paris News Update \#23. Penang: Third World Network. 
Beck, S. (2015). Science. In Karen Bäckstrand \& Eva Lövbrand (Eds.), Research handbook on climate governance (pp. 286-296). Cheltenham: Edward Elgar.

Böttcher, H., \& Graichen, J. (2015). Impacts on the EU 2030 climate target of including LULUCF in the climate and energy policy framework. Berlin: Öko-Institut e.V.

Briner, G., \& Konrad, S. (2014). Planting the foundations of a Post-2020 land sector reporting and accounting framework. Climate Change Expert Group, OECD.

Daviet, F., \& Goers, L. (2009). Forests in the balance sheet. Washington, DC: World Resources Institute.

den Elzen, M., \& Lucas, P. (2003). FAIR 2.0: A decision-support model to assess the environmental and economic consequences of future climate regimes. Netherlands Environmental Assessment Agency (MNP).

Dutschke, M. (2013). Key issues in REDD+ verification: Study commissioned by CIFOR. Occasional paper 88. CIFOR: Bogor, Indonesia.

Ecosystems Climate Alliance. (2009). De-constructing LULUCF and its perversities. Global Witness; Wetlands International; Rainforest Action Network; The Wilderness Society.

Earth Negotiations Bulletin (ENB). (1997). Report of the third conference of the parties to the United Nations framework convention on climate change: 1-11 December, 1997. International Institute for Sustainable Development.

Estrada, M., Lee, D., Murray, B., OSullivan, R., Penman, J., \& Streck, C. (2014). Land use in a future climate agreement. Prepared with support from cooperative agreement \#S-LMAQM-13-CA-1128 with U.S. Department of State.

Fogel, C. (2005). Biotic carbon sequestration and the Kyoto Protocol: The construction of global knowledge by the intergovernmental panel on climate change. International Environmental Agreements: Politics, Law and Economics, 5(2), 191-210.

Fry, I. (2002). Twists and turns in the jungle: Exploring the evolution of land use, land-use change and forestry decisions within the Kyoto Protocol. RECIEL, 11(2), 159-168.

Fry, I. (2007). More twists, turns and stumbles in the jungle: A further exploration of land use, land-use change and forestry decisions within the Kyoto Protocol. RECIEL, 16(3), 1-15.

Grassi, G., \& Dentener, F. (2015). Quantifying the contribution of the land use sector to the Paris climate agreement, EUR 27561.

Gupta, A. (2011). An evolving science-society contract in India: The search for legitimacy in anticipatory risk governance. Food Policy, 36(6), 736-741.

Gupta, A., Andresen, S., Siebenhüner, B., \& Biermann, F. (2012). Science networks. In Frank Biermann \& Philipp Pattberg (Eds.), Global environmental governance reconsidered (pp. 69-93). Cambridge, MA: MIT Press.

Gupta, A., \& Mason, M. (2016). Disclosing or obscuring? The politics of transparency in global climate governance. Current Opinion in Environmental Sustainability, 18, 82-90.

Hansen, J., Karecha, P., Sata, M., et al. (2013). Assessing "Dangerous climate change": Required reduction of carbon emissions to protect young people, future generations and nature. PLOS ONE, 8(12), 1-26.

Höhne, N., Wartmann, S., Herold, A., \& Freibauer, A. (2007). The rules for land use, land use change and forestry under the Kyoto Protocol-Lessons learned for the future climate negotiations. Environmental Science \& Policy, 10(4), 353-369.

IPCC (2014). Smith P., et al. Chapter 11: Agriculture, forestry and other land use (AFOLU). In Edenhofer, O., R. et al. (Eds.), Climate change 2014: Mitigation of climate change. Contribution of working group III to the fifth assessment report of the intergovernmental panel on climate change. Cambridge University Press.

Iversen, P., Lee, D., \& Rocha, M. (2014). Understanding land use in the UNFCCC.

Jasanoff, S. (1998). Fifth Estate: Science advisors as policy makers. Cambridge MA: Harvard University Press.

Jasanoff, S. (Ed.). (2004). States of knowledge: The coproduction of science and the social order. London: Routledge.

Jasnoff, S. (2003). (No?) Accounting for expertise. Science and Public Policy, 30(3), 157-162.

Lee, D., Penman, J., \& Streck, C. (2015). Land use in a future climate agreement. Washington DC: Climate Focus.

Levin, K., Morgan, J., \& Song, J. (2015). INSIDER: Understanding the Paris agreement's long-term goal to limit global warming. Washington, DC: World Resources Institute.

Lövbrand, E. (2004). Bridging political expectations and scientific limitations in climate risk managementOn the uncertain effects of international carbon sink policies. Climatic Change, 67, 1-12.

Lövbrand, E. (2009). Revisiting the politics of expertise in light of the Kyoto negotiations on land use change and forestry. Forest Policy and Economics, 11(5-6), 404-412. 
Macintosh, A. (2011). The Australia clause and REDD: A cautionary tale. Climatic Change, 112(2), $169-188$.

Mackey, B., Prentice, I. C., Steffen, W., et al. (2013). Untangling the confusion around land carbon science and climate change mitigation policy. Nature Climate Change, 3(6), 552-557.

Parker, C., Merger, E., Streck, C., et al. (2014). The land-use sector within the post-2020 climate regime. Copenhagen: Norden.

Powlson, D. S., Whitmore, A. P., \& Goulding, C. J. (2011). Soil carbon sequestration to mitigate climate change: A critical re-examination to identify the true and the false. European Journal of Soil Science, $62(1), 42-55$.

Rocha, M., Hare, B., Cantzler, J., et al. (2015). New Zealand deploys creative accounting to allow emissions to rise. Berlin: Climate Action Tracker.

Sarewitz, D. (2004). How science makes environmental controversies worse. Environmental Science \& Policy, 7(4), 385-403.

Schaeffer, M., Hare, B., Rocha, M., \& Rogelj, J. (2013). Adequacy and feasibility of the $1.5^{\circ} \mathrm{C}$ long-term global limit. Brussels: Climate Action Network Europe.

Schlamadinger, B., Bird, N., Johns, T., et al. (2007). A synopsis of land use, land-use change and forestry (LULUCF) under the Kyoto Protocol and Marrakech Accords. Environmental Science \& Policy, 10(4), 271-282.

UNFCCC. (1997). Adoption of the Kyoto Protocol to the United Nations Framework Convention on Climate Change, decision 1/CP.3 (FCCC/CP/1997/7/Add.1). Bonn: United Nations Framework Convention on Climate Change Secretariat.

UNFCCC. (2015). Adoption of the Paris Agreement, decision 1/CP.21 (FCCC/CP/2015/10/Add.1). Bonn: United Nations Framework Convention on Climate Change Secretariat.

UNFCCC. (2016). Aggregate effect of the intended nationally determined contributions: An update. Synthesis report by the Secretariat.

Weingart, P. (1999). Scientific expertise and political accountability: Paradoxes of science in politics. Science and Public Policy, 26(3), 151-161. 